\begin{tabular}{|c|c|c|}
\hline 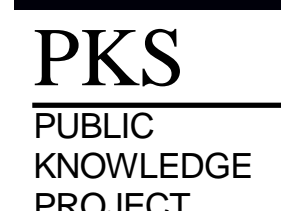 & $\begin{array}{c}\text { REVISTA DE GEOGRAFIA } \\
\text { (RECIFE) } \\
\text { http://www.revista.ufpe.br/revistageografia }\end{array}$ & $\begin{array}{l}\text { OJS } \\
\text { OPEN } \\
\text { JOUNAL } \\
\text { SYSTEMS }\end{array}$ \\
\hline
\end{tabular}

\title{
EMPREGO DA PEDOMETRIA NA DELIMITAÇÃO DOS SOLOS DE PLANÍCIE FLUVIAL DO BAIXO CURSO DA BACIA HIDROGRÁFICA DO RIO IVAÍ (NOROESTE DO PARANÁ)
}

\author{
${ }^{1}$ Alexei Nowatzki; ${ }^{2}$ José Guilherme Oliveira; ${ }^{3}$ Marcelo Ng Wei Ban Hung; ${ }^{4}$ \\ Leonardo José Cordeiro Santos
}

\begin{abstract}
${ }^{1}$ Doutorando pelo Programa de Pós-Graduação em Geografia da UFPR. E-mail: nowatzki.a@gmail.com ${ }^{2}$ Mestrando pelo Programa de Pós-Graduação em Geografia da UFPR. E-mail: joseguilhermegeo@gmail.com

${ }^{3}$ Mestrando pelo Programa de Pós-Graduação em Geografia da UFPR. E-mail: marcelo.hung1@gmail.com

${ }^{4}$ Professor Associado III no departamento de Geografia da UFPR. E-mail: santos.ufpr@gmail.com
\end{abstract}

Artigo recebido em 20/10/2017 e aceito em 09/03/2018

\begin{abstract}
RESUMO
Planícies fluviais são porções da paisagem localizadas nos vales, constituídas de sedimentos aluviais e sujeitas a alagamentos periódicos. Sua funcionalidade ambiental se relaciona à formação de corredores de biodiversidade, aporte de nutrientes aos cursos d'água, filtragem, estabilização das margens dos rios evitando a erosão e assoreamento. O mapeamento de solos nessas planícies é normalmente uma atividade difícil e complexa, em virtude principalmente dos acessos precários em campo. O baixo curso da bacia hidrográfica do rio Ivaí, área de estudo deste trabalho, apresenta uma extensa planície fluvial com ocorrência de Neossolos Flúvicos, Gleissolos e Organossolos. A pedometria pode contribuir na delimitação dessas áreas, mapeando com precisão e em escalas de detalhe. O objetivo deste trabalho foi aplicar o método de tabulação cruzada na integração dos atributos topográficos, índice de posição topográfica e índice topográfico de umidade modificado, a fim de mapear porções da paisagem com solos característicos da planície fluvial. Como resultado, foram gerados dois grupos: solos de planície fluvial ( $11 \%$ da área de estudo) e solos de planalto (com $89 \%$ ). Essa fase não possibilita a distinção das classes de solos, pois para isso etapas pontuais de campo associadas a fotointerpretação da área são necessárias.
\end{abstract}

Palavras-chave: Planícies fluviais; Pedometria; Tabulação cruzada.

\section{USE OF PEDOMETRICS IN THE DELIMITATION OF THE FLUVIAL PLAIN SOILS OF LOWER COURSE OF THE HYDROGRAPHIC BASIN OF IVAÍ RIVER (NORTHWEST OF PARANÁ)}

\begin{abstract}
Fluvial plains are landscape sections located in valleys, composed by alluvial sediments and subject to periodic flooding. Its environmental functionality is related to the biodiversity corridors formation, nutrient supply to watercourses, filtering, stabilization of riverbanks, avoiding erosion and siltation. The mapping soils in these plains is usually a difficult and complex activity, mainly due to precarious accesses in the fieldwork. The low course of the river basin of the Ivaí river, study area of this work, presents an extensive fluvial plain with occurrence of Fluvisols, Gleysoils and Histosols. Pedometrics can contribute in the delimitation of these areas, mapping accurately and in detailed scales. The objective of this work was to apply the cross tabulation method to the integration of topographic attributes, topographical position index and modified wetness index in order to map portions of the landscape with soils characteristic of the fluvial plain. As a result, two groups were
\end{abstract}


generated: river plain soils (11\% of the study area) and plateau soils (with 89\%). This phase does not make it possible to distinguish the soil classes, since for this purpose, field stages associated with photointerpretation of the area are necessary.

Key-words: Fluvial plains; Pedometrics; Cross tabulation.

\section{INTRODUÇÃO}

Planícies de inundação referem-se às porções do vale fluvial constituídas de sedimentos aluviais que circundam o curso de água e são periodicamente inundadas pela dinâmica da rede de drenagem, permanecendo o nível freático próximo da superfície do solo grande parte do ano (IBGE, 2009; CHRISTOFOLETTI, 2011).

Esses ambientes hidromórficos são propícios ao desenvolvimento do processo pedogenético de gleização cuja redução do ferro, em condições anaeróbias, possibilita a formação de horizontes acinzentados com ou sem mosqueamento. Nessas situações pode ocorrer também acúmulo de resíduos orgânicos e a formação de Organossolos (LEPSCH, 2011; EMBRAPA, 2013).

Esses locais se caracterizam ainda pela presença de camadas estratificadas, e/ou distribuição irregular do conteúdo de carbono orgânico em profundidade, não relacionada a processos pedogenéticos, empregados na identificação dos Neossolos Flúvicos (EMBRAPA, 2013; IBGE, 2015).

Essas porções da paisagem estão relacionadas diretamente a qualidade dos recursos hídricos, sendo imprescindível a sua preservação. Segundo Nowatzki et al. (2010, 2016), a funcionalidade ambiental das zonas ripárias se relaciona à formação de corredores de biodiversidade, a estabilização das margens dos rios, ao controle do aporte de nutrientes e de produtos químicos aos cursos d'água, a filtragem e ao controle da alteração da temperatura para o ecossistema aquático e a formação de barreiras que evitam carregamento de sedimentos para os cursos d'água, e consequentemente, o assoreamento dos corpos hídricos. Esses autores apontam ainda que quando um rio não possui mata ciliar, fica suscetível ao desenvolvimento de processos erosivos mais frequentes e intensos ao longo de suas margens e que podem provocar danos às atividades agrícolas e pecuárias, bem como alterar profundamente as relações ecológicas da fauna e flora local.

Um exemplo da importância ambiental que essas áreas oferecem foi dada pelo estado do Paraná, a partir da criação de uma Resolução Conjunta IBAMA/SEMA/IAP n 005 (PARANÁ, 2008) que conceitua as áreas úmidas como "segmento de paisagem constituído por solos hidromórficos" (PARANÁ, 2008, p.3), ou seja, o solo naturalmente originado pela $\frac{\text { presença de água subsuperficial, geralmente, dentro de } 50 \mathrm{~cm} \text { a partir da superfície. Essa }}{\text { Nowatzki et al. } 2018}$ 
resolução se baseou na concepção do regime hídrico dos solos para avaliar as áreas úmidas e seus entornos protetivos.

O mapeamento de solos nessas planícies de inundação é normalmente uma atividade difícil e complexa, em virtude principalmente dos acessos precários em campo. Essa dificuldade se reflete, por exemplo, na porcentagem de Organossolos e Gleissolos mapeados para o território brasileiro, certamente inferior a realidade.

Assim, o objetivo desse trabalho foi usar a pedometria na identificação e na delimitação da planície fluvial, na escala 1:50.000 do baixo curso da bacia hidrográfica do rio Ivaí $\left(9.601 \mathrm{~km}^{2}\right.$ ) (Figura 1), localizada no noroeste do estado do Paraná.

Figura 1 - Localização do baixo curso da bacia hidrográfica do rio Ivaí

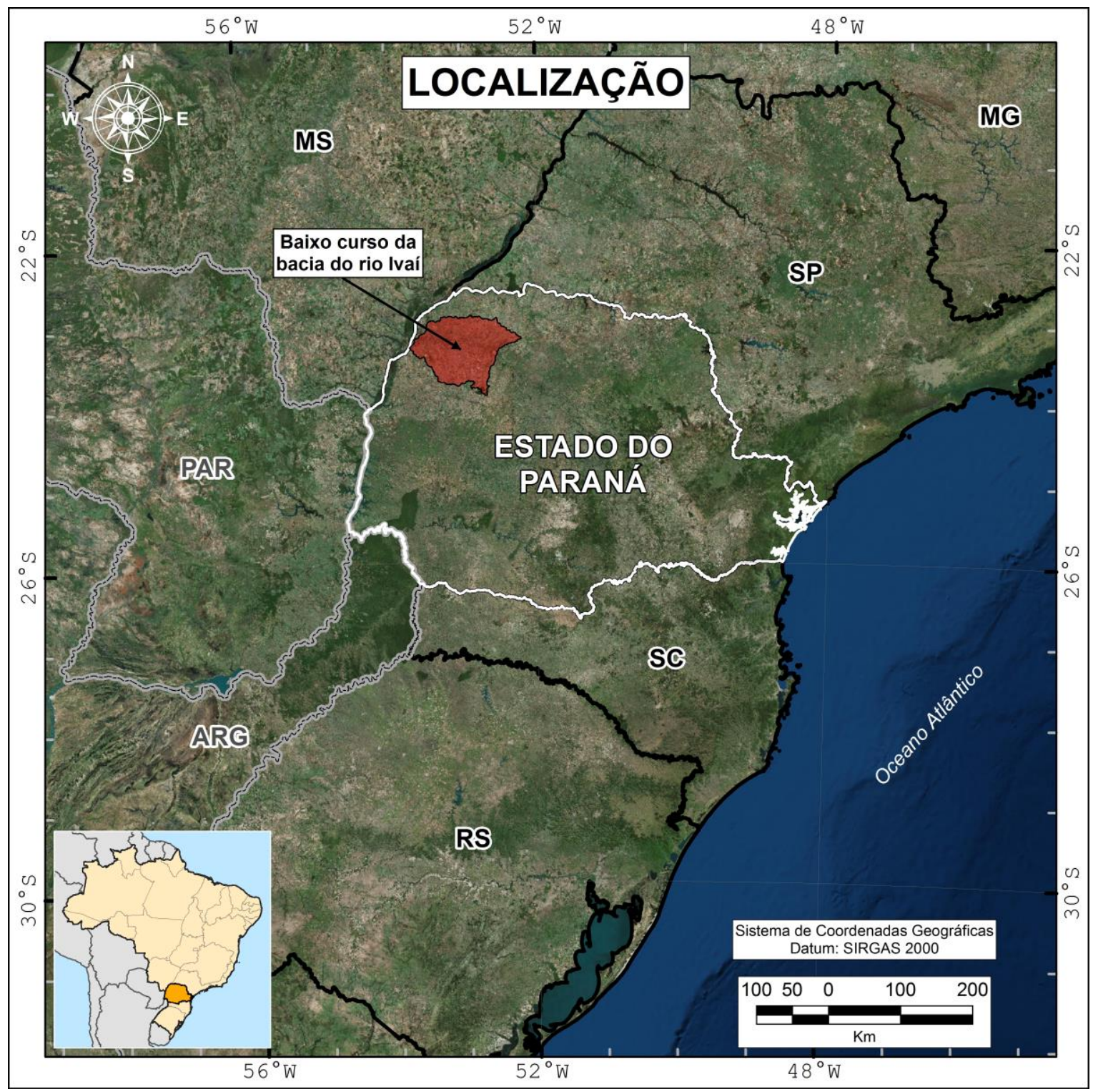


Modelos quantitativos, usados em levantamentos pedológicos e que auxiliam na delimitação e na distribuição espacial dos solos, são categorizados em um ramo da ciência do solo conhecido como Pedometria (MCBRATNEY et al., 2000; SILVEIRA et al., 2013; DALMOLIN; TEN CATEN, 2015). Conceituada como a "aplicação de métodos matemáticos e estatísticos para a modelagem quantitativa dos solos, com o objetivo de analisar sua distribuição, propriedades e comportamentos" (SAMUEL-ROSA, 2013, p.3), a pedometria envolve a ciência do solo, a estatística-matemática e a ciência da geoinformação, uma vez que está relacionada à abordagem quantitativa, à qualidade da informação do solo com respeito a variabilidade, à incerteza e confiabilidade (BURROUGHS et al., 1994; HENGL, 2003).

A partir da Pedometria, surgiu o conceito de Mapeamento Digital de Solos (MDS) que é a criação de sistemas de informação espacial de solos por meio de modelos numéricos, inferindo a variação espacial e temporal de classes e atributos de solos a partir de observações de campo e variáveis do meio físico correlacionadas (McBRATNEY et al. 2003).

Para o MDS em áreas de planícies fluviais pode-se utilizar atributos topográficos (AT) como o índice de posição topográfica (IPT), no qual segmenta a vertente em áreas próximas dos divisores, terços médios de vertentes e fundos de vales (WEISS, 2001; SILVEIRA; SILVEIRA, 2016); e o índice topográfico de umidade modificado (ITM) que é usado para caracterizar a distribuição espacial de áreas com maior probabilidade de saturação hídrica do solo (MOORE et al., 1993; HUNG et al., 2017).

\section{Caracterização da área de estudo}

Ao longo do baixo curso da bacia hidrográfica do rio Ivaí são encontrados em sua grande maioria arenitos do Grupo Caiuá (deposições eólicas do período Cretáceo da era Mesozoica). Esse grupo sedimentar é composto pelas formações Goio Erê e Rio Paraná (em sua grande maioria na área de estudo). Ainda ocorrem rochas ígneas extrusivas do Grupo São Bento (Formação Serra Geral) e também Sedimentos Cenozoicos (depósitos aluviais do quaternário) (FERNANDES; COIMBRA, 1994).

De acordo com o mapa geomorfológico do estado do Paraná (1:250.000), a área de estudo engloba os planaltos de Paranavaí, Umuarama e Campo Mourão bem como a classe de planície fluvial (SANTOS et al., 2006). As classes de solos (1:250.000) que ocorrem, segundo EMBRAPA (2007), são majoritariamente dos Argissolos (P) e dos Latossolos (P) (ocupando aproximadamente $90 \%$ da área). Ainda ocorrem, Nitossolos (N), Neossolos (R), Organossolos (O) e Gleissolos (G) (aproximadamente 10\% para essas quatro classes juntas). 
No âmbito do mapeamento dos sistemas pedológicos de Nakashima (1999), seis sistemas foram identificados, sendo os mais significativos: SP-II no setor norte da área de estudo com maior presença dos Latossolos em detrimento dos Argissolos; SP-IV no setor sul da área com uma participação mais significativa dos Argissolos; SP-VI representando a planície de inundação do rio Ivaí.

Todas essas informações do meio físico do baixo curso da bacia do Ivaí estão ilustradas na Figura 2.

Figura 2 - Geologia, compartimentos geomorfológicos, pedologia e sistemas pedológicos da área de estudo
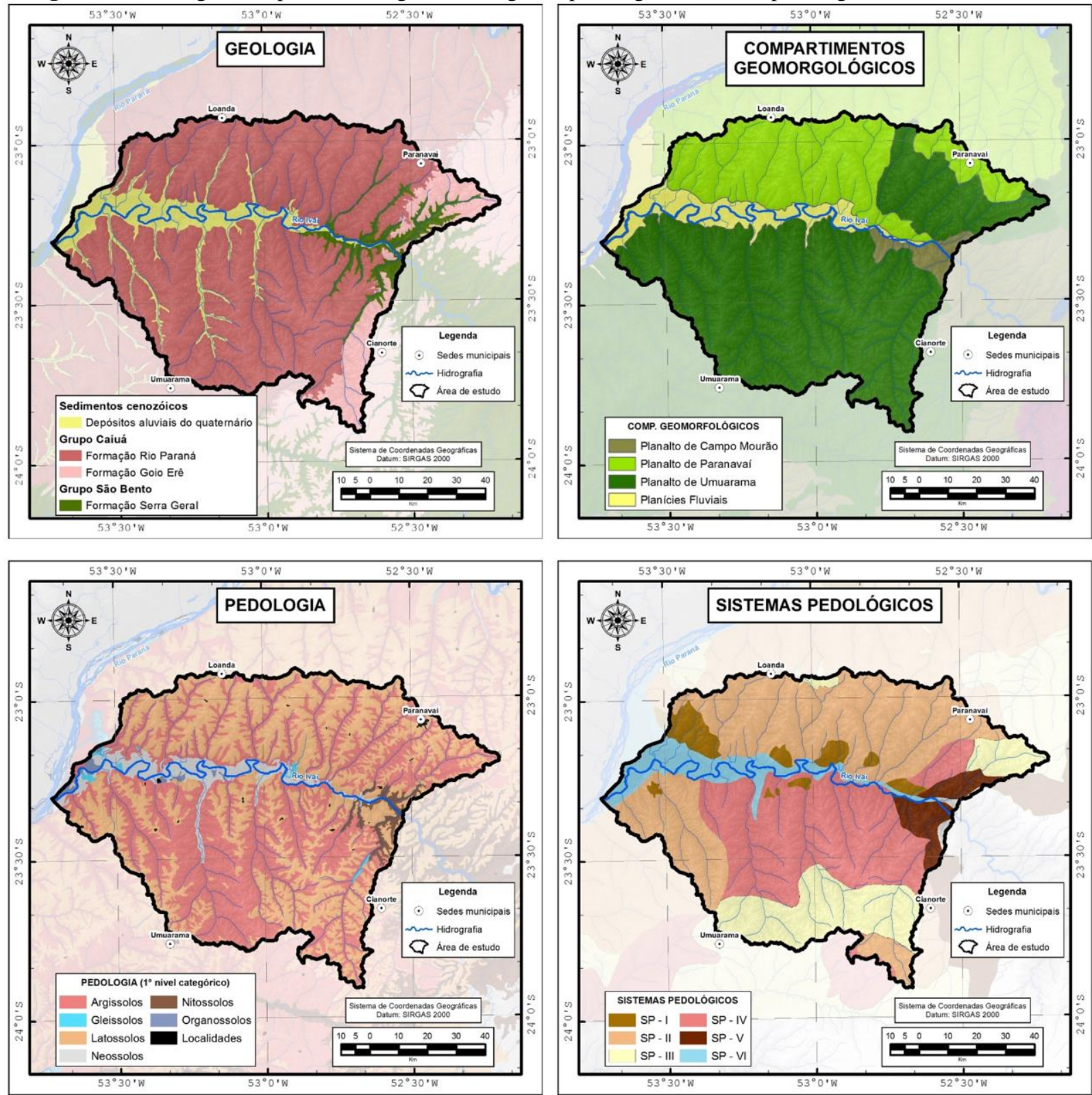


\section{MATERIAL E MÉTODOS}

A base de dados utilizada para o desenvolvimento dessa pesquisa se restringiu as curvas de nível (com equidistância de $20 \mathrm{~m}$ ) e pontos cotados, disponibilizados pelo Instituto de Terras Cartografia e Geociências (ITCG) na escala 50.000; e dados de hidrografia (Instituto das Águas do Paraná). Todos os produtos cartográficos propostos no objetivo deste trabalho foram gerados a partir desses dados e organizados em ambiente SIG (Sistema de Informação Geográfica). A resolução horizontal (tamanho de pixel) do MDT foi de uma célula de $20 \mathrm{~m}$, pautado no valor da equidistância das curvas de nível da base de dados altimétricos.

O MDT foi gerado por meio do software ArcGISTM 10.3 com a ferramenta Topo to Raster disponível no módulo Spacial Analyst Tools. Essa ferramenta se baseia no método de interpolação denominado Topogrid proposto por Hutchinson (1989) na qual utiliza um algoritmo que cria superfícies topográficas hidrologicamente consistentes (SILVA et al., 2017).

Inicialmente, para a identificação da planície fluvial, foi utilizada como parâmetro de análise, informações do meio físico por meio da espacialização de: 1) geologia do grupo Caiuá (classe de sedimentos cenozoicos) (FERNANDES; COIMBRA, 1994); 2) planície fluvial presente no mapeamento geomorfológico do estado do Paraná (SANTOS et al. 2006); 3) Neossolos Flúvicos (RY), Gleissolos (G) e Organossolos (O) do mapeamento da EMBRAPA (2007); e 4) sistema pedológico (SP) de planícies de inundação (SP-VI) de Nakashima (1999).

Para a aplicação do MDS da planície fluvial foram empregados os atributos topográficos (AT): índice de posição topográfica (IPT) e índice topográfico de umidade modificado (ITM). O IPT é um atributo topográfico derivado de um algoritmo que mensura a diferença entre a elevação de um ponto central $(p t)$ e a média da elevação ao seu redor $(\mu)$ com um raio predeterminado (WEISS, 2001; SILVEIRA; SILVEIRA, 2016). No ArcGIS, foi realizada a Equação 1.

$$
I P T=p t-\mu
$$

onde:

$p t=$ ponto central

$\mu=$ média da elevação.

Os valores positivos obtidos pelo IPT representam locais mais elevados que a média do seu entorno, caracterizando, em geral, os divisores topográficos, enquanto que os valores 
negativos representam os locais mais rebaixados em relação à sua vizinhança, caracterizando vales ou depressões. Os valores próximos a zero obtidos pelo IPT representam as superfícies de declive constante (SILVEIRA; SILVEIRA, 2016). A Figura 3 ilustra a diferença entre os valores encontrados no IPT, conforme o tamanho do raio predeterminado.

Figura 3 - Índice de posição topográfica (IPT)

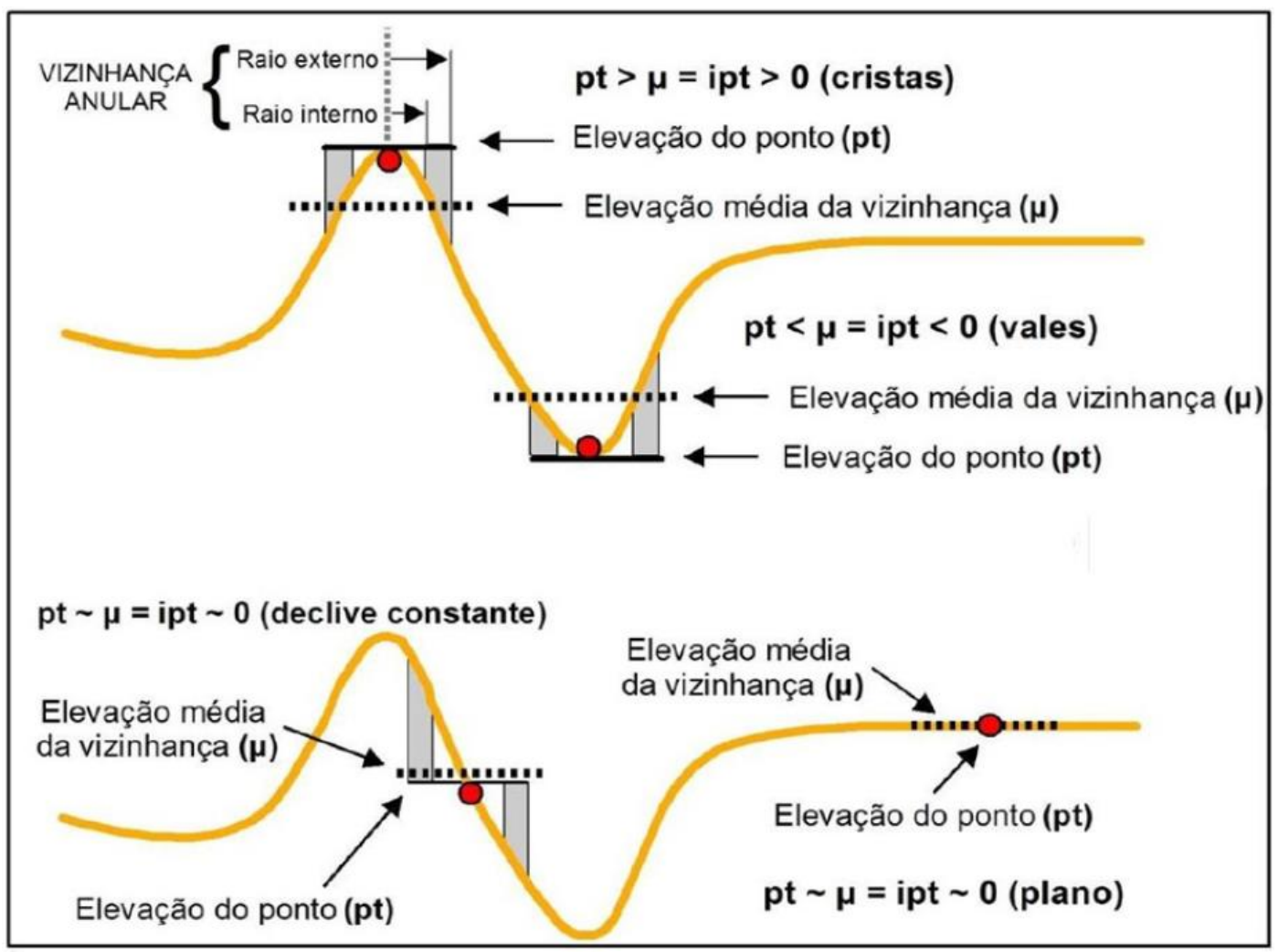

Fonte: Silveira e Silveira (2016) adaptado de Weiss (2001)

A análise de vizinhança pode ser feita por uma janela circular, anular (proposta original), retangular ou irregular (WEISS, 2001). Foram testados diversos valores de raio e o de $50 \mathrm{~km}$ apresentou melhor segmentação para a planície do rio Ivaí.

Por sua vez, o índice topográfico de umidade (ITU) caracteriza a distribuição de áreas com maior probabilidade de saturação hídrica do solo (MOORE et al., 1993; SILVEIRA et al., 2013). Esse índice é obtido a partir da razão entre a área de contribuição e a tangente da declividade local (Equação 2), e foi elaborado a partir do MDT por meio do software SAGA GISTM 5.0.0.

$$
I T U=\ln \frac{A C}{\tan \beta}
$$

onde:

$\mathrm{AC}=$ área de contribuição

$\beta=$ clinografia 
Böhner e Selige (2006) propuseram uma modificação na área de contribuição estabelecendo um limite superior para as áreas de contribuição para cada valor de declividade é determinado uma área de contribuição máxima. Desta maneira, valores maiores que esses limites são homogeneizados, principalmente em porções de fundo de vale, cujo o objetivo é minimizar a existência de valores aleatórios e fora do padrão em áreas mais planas (HUNG et al., 2017). A Equação 3 representa esse índice com a área de contribuição modificada (ACM).

$$
I T M=\ln \frac{A C M}{\tan \beta}
$$

onde:

$\mathrm{ACM}=$ área de contribuição modificada

$\beta=$ clinografia

Portanto, o ITM considera a razão entre a ACM (Equação 4) e a tangente da declividade local e foi utilizado para identificar as porções da área de estudo que representam as planícies fluviais do baixo curso do rio Ivaí.

$$
A C M=A C_{\max }\left(\frac{1}{15}\right)^{\beta \exp \left(15^{\beta}\right)}
$$

onde:

$\mathrm{AC}_{\max }=$ área de contribuição máxima para cada valor de declividade.

Cabe destacar que o ITM é uma derivação do índice topográfico de umidade (ITU) e prevê uma melhor representação das áreas com maior probabilidade de saturação em áreas mais planas, uma vez que o ITU cria áreas de inconsistência em porções com declividades muito baixas (BÖHNER; SELIGE, 2006; HUNG et al., 2017). Por meio da Figura 4 é possível fazer uma comparação entre os índices. 
Figura 4 - Comparação entre o índice topográfico de umidade e o índice topográfico de umidade modificado

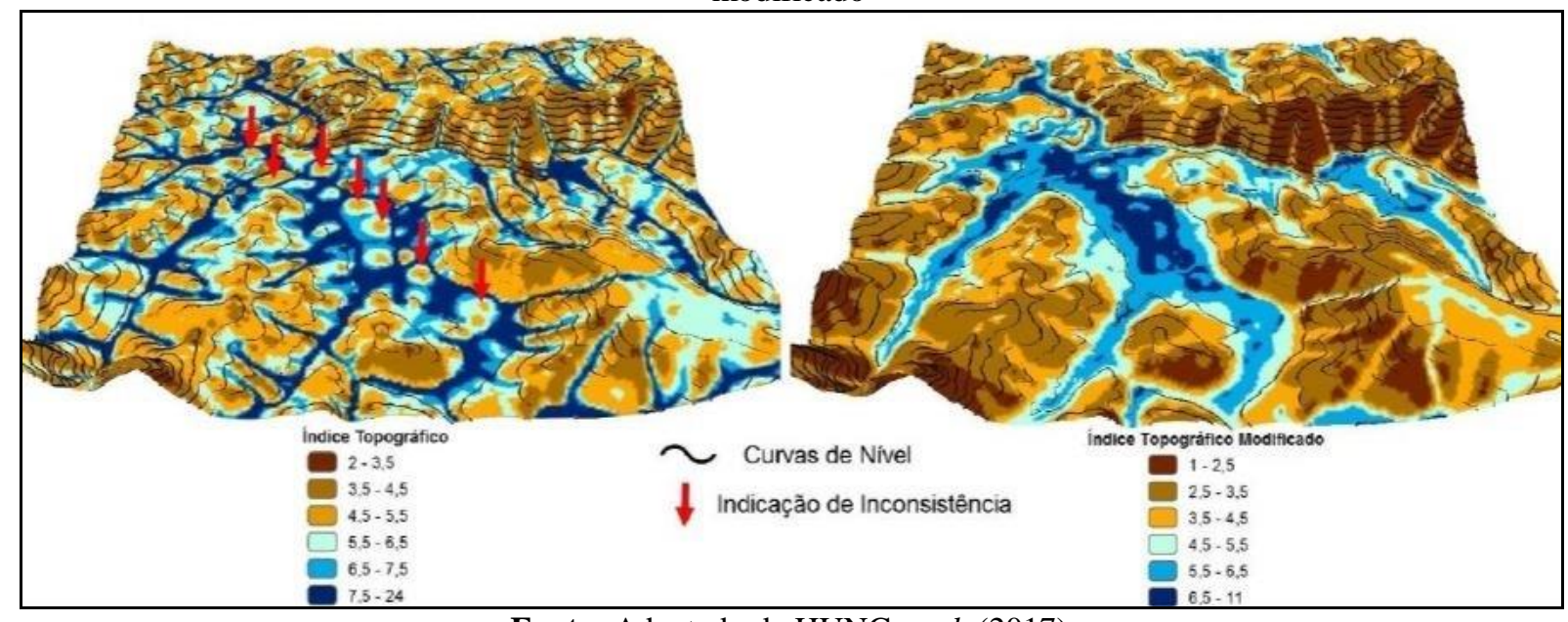

Fonte: Adaptado de HUNG et al. (2017)

Com o intuito de auxiliar a etapa de discretização dos intervalos dos atributos topográficos, foram examinados diversos perfis transversais com valores de hipsometria e clinografia ao longo da planície fluvial do rio Ivaí. Em seguida, foram selecionadas dois que representassem os limites dessa planície, um à jusante da área de estudo (Perfil 01) e outro à montante (Perfil 02), com aproximados $20 \mathrm{~km}$ de extensão. A partir dessas análises foi possível separar os AT nas seguintes classes: 1) solos de planície fluvial; 2) solos de planalto. Os valores das classes discretizadas estão sintetizados na matriz de tabulação no Quadro 1.

Quadro 1 - Matriz de tabulação dos atributos topográficos

\begin{tabular}{|c|c|c|c|c|c|}
\hline \multirow{4}{*}{$\begin{array}{c}\text { Atributo } \\
\text { Topográfico }\end{array}$} & & & & \multicolumn{2}{|c|}{ IPT } \\
\hline & \multirow[t]{3}{*}{ Solos } & & & $\begin{array}{l}\text { Planície } \\
\text { fluvial }\end{array}$ & Planalto \\
\hline & & \multirow[t]{2}{*}{ Intervalos } & & -137 a -70 & $-70 a+193$ \\
\hline & & & Classe & 1 & 2 \\
\hline \multirow{2}{*}{ ITM } & Planalto & 7 a 15 & 1 & 11 & 12 \\
\hline & $\begin{array}{c}\text { Planície } \\
\text { fluvial }\end{array}$ & 15 a 25 & 2 & 21 & 22 \\
\hline
\end{tabular}

A etapa final consistiu em aplicar o método de tabulação cruzada (álgebra entre mapas) (TOMLIN, 1994) para os dois atributos, combinando as classes consideradas como solos de planície fluvial, ou seja, classe 2 do ITM com a 1 do IPT. As outras classes foram classificadas como solos de planalto, tendo em vista que pelo mapeamento da EMBRAPA 
(2007) existem Latossolos e Argissolos dentro da área de estudo, assim como evidenciaram Nowatzki et al., (2017) por meio de um MDS na região noroeste do Paraná enfatizando a passagem lateral desses dois solos.

\section{RESULTADOS E DISCUSSÕES}

A análise hipsométrica do perfil transversal 01 (localizado à jusante do rio Ivaí) permitiu apresentar os valores altimétricos que evidenciam o início e fim da planície fluvial (250 $\mathrm{m}$ de altitude e extensão de $10 \mathrm{~km}$ aproximadamente). O perfil 02 apresentou a mesma altitude, contudo a extensão da planície se mostrou bem menor (com cerca de $3 \mathrm{~km}$ apenas), por estar situado mais à montante em relação ao primeiro, conforme apontam as setas indicadas na Figura 4.

Figura 4 - Perfis de análise hipsométrica
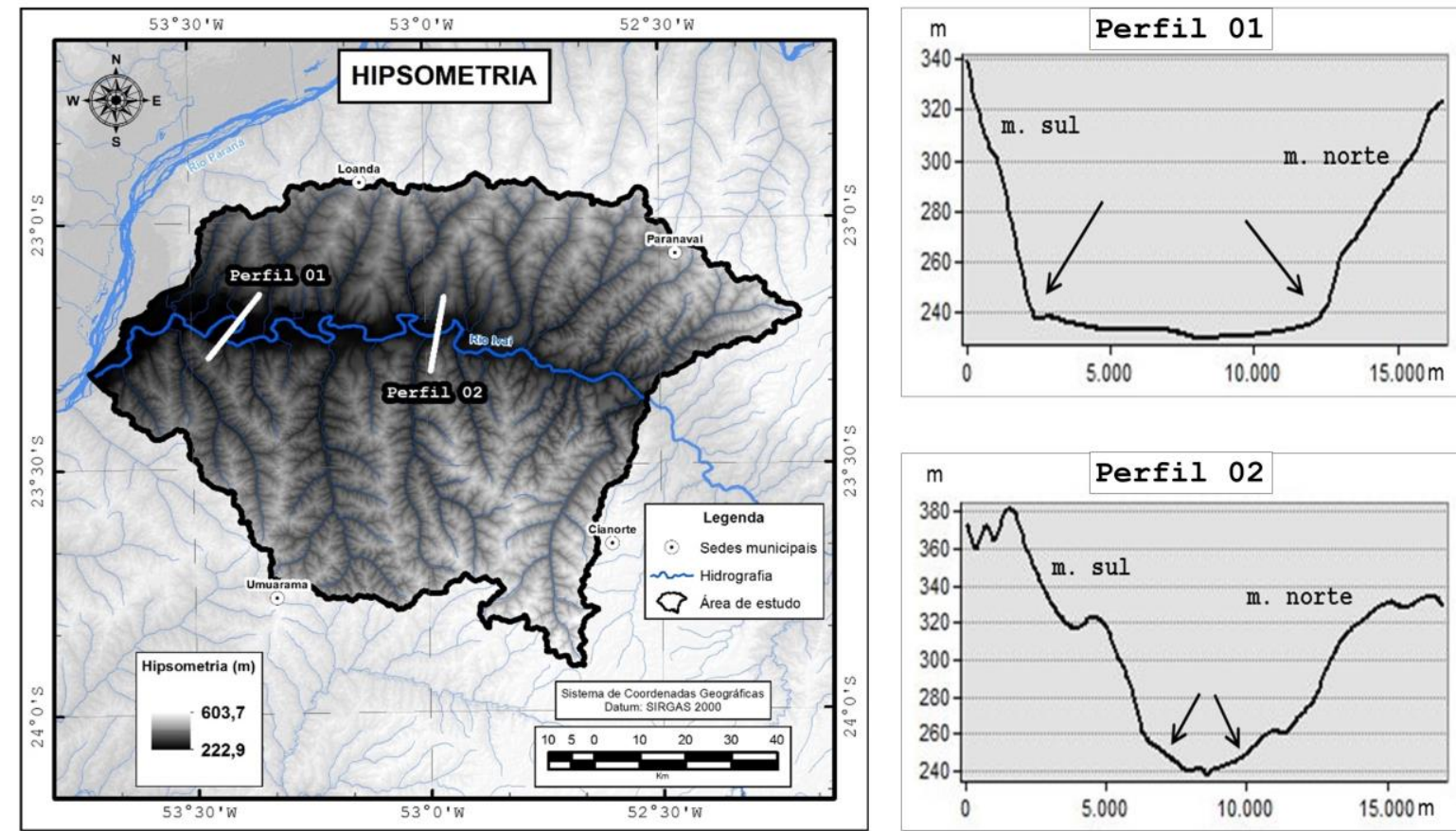

A análise clinográfica dos perfis possibilitou observar que os valores diminuem quando entra no contexto de planície fluvial, conforme indicam as setas (Figura 5). Os valores abaixo de $2 \%$ de clinografia indicam a início da planície fluvial e assim como na hipsometria, o perfil 01 apresentou uma extensão maior que o perfil 02. 
Figura 5 - Perfis de análise clinográfica
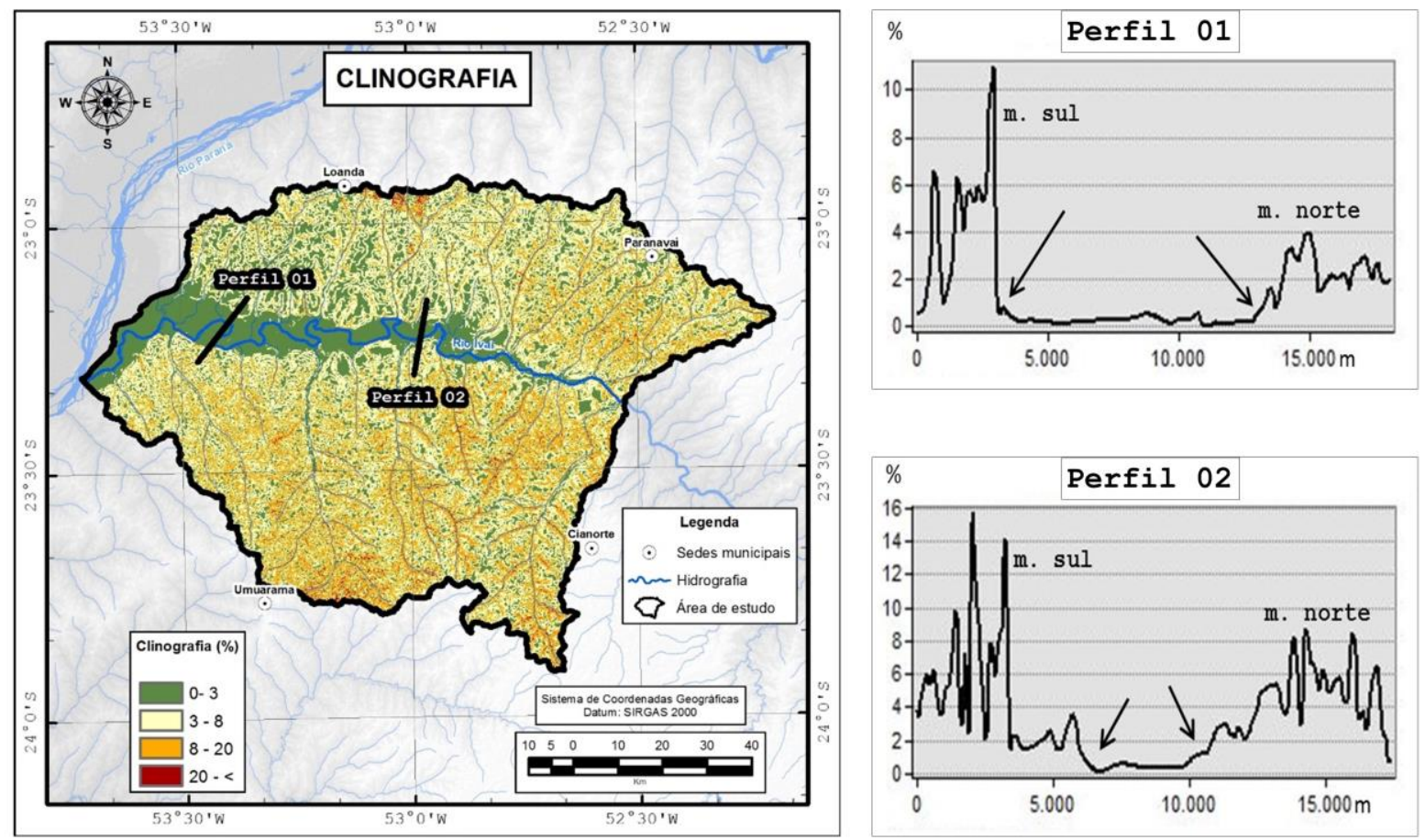

Foi possível destacar ainda que os valores de clinografia nos dois perfis são em geral maiores no setor sul (margem esquerda do rio Ivaí), em relação ao setor norte, o que tem relação com a distribuição dos Argissolos na área de estudo, que ocorrem associados as declividades mais acentuadas em todo a região noroeste do estado do Paraná, evidenciado no SP- IV de Nakashima (1999).

O índice topográfico de umidade modificado apresentou valores entre 7 e 25 (quanto mais alto o valor, maiores são as condições de saturação hídrica no solo), ilustrados na Figura 6. A discretização desse AT foi de 7 a 15 para porções de áreas com ocorrência de solos de planalto (classe 1 de ITM) e 15 a 25 para porções da área de estudo com ocorrência de solos de planície fluvial (classe 2 de ITM). Em relação a distribuição e proporção das duas áreas mapeadas, nota-se que para a classe 1 o ITM possui $7.176,78 \mathrm{~km}^{2}(74,75 \%$ do total da área que é de $\left.9.601,34 \mathrm{~km}^{2}\right)$ e a classe 2 tem $2.424,56 \mathrm{~km}^{2}$ (25,25\% da área). 
Figura 6 - O índice topográfico de umidade modificado

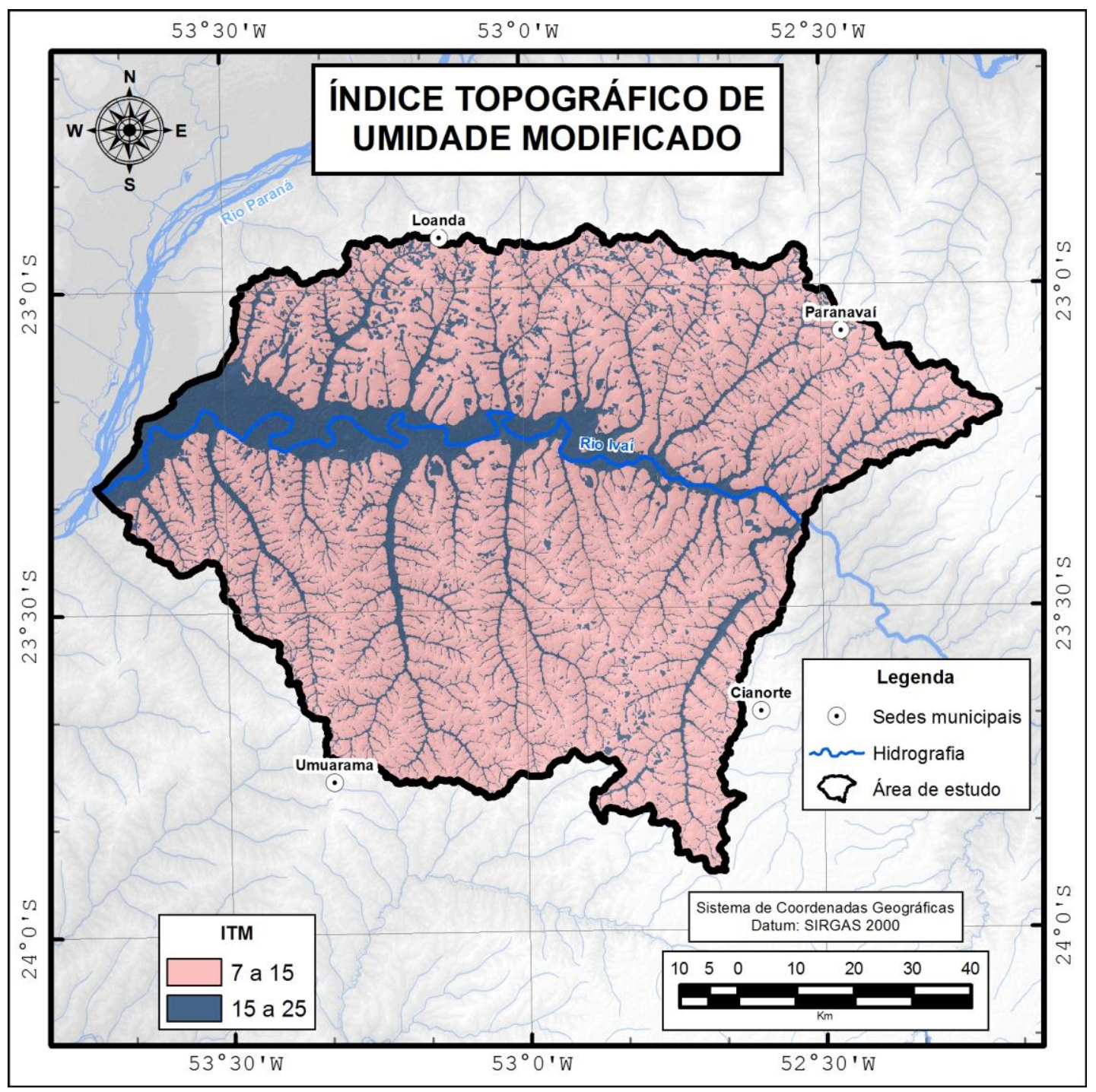

Por sua vez, o índice de posição topográfica (Figura 7) apresentou valores entre -137 e 193 (valores negativos representam porções de fundo de vale e positivas porções de terço médio de vertente e divisores topográficos). A discretização do IPT foi de -137 a - 70 para a classe de solos de planície fluvial (classe 1 de IPT) e -70 a 193 para a classe de solos de planalto (classe 2 de IPT). Já a classe 1 do IPT tem um valor de 1.214,61 km² $(12,65 \%$ do total da área), sendo que a classe 2 possui $8.386,73 \mathrm{~km}^{2}(87,35 \%)$. 
Figura 7 - O índice de posição topográfica

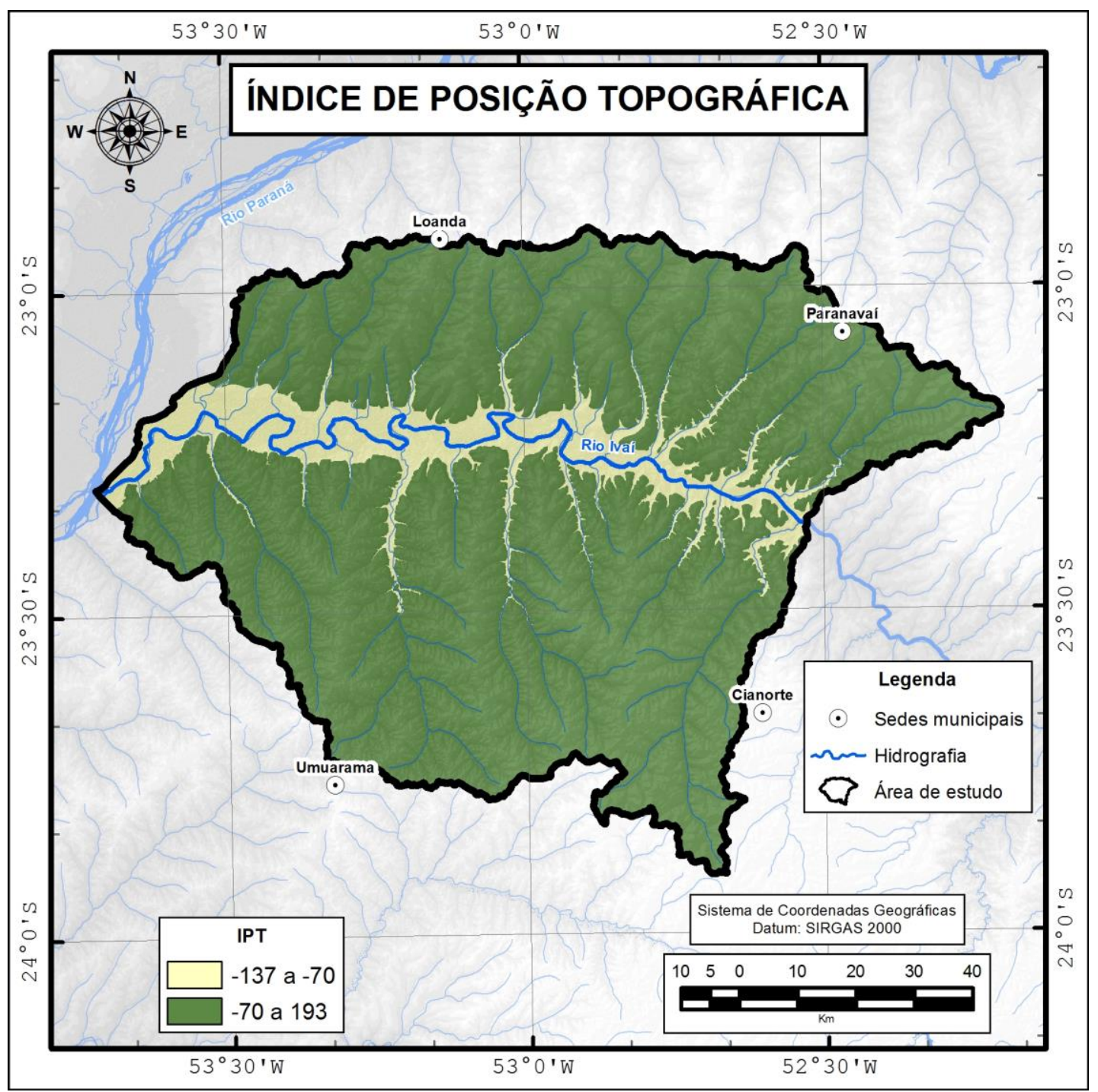

A Figura 8 ilustra o resultado final do agrupamento dos solos gerados por pedometria por meio da tabulação cruzada entre os atributos ITM e IPT. O grupo de solos de planície fluvial (Neossolos Flúvicos, Gleissolos e Organossolos) apresenta área de 1.053 km² (equivalente a $11 \%$ da área de estudo). Já a classe de solos de planalto (Latossolos e Argissolos) tem $8.549 \mathrm{~km}^{2}$ (89\% da área). 
Figura 8 - Grupos de solos gerados por Pedometria do baixo curso da bacia hidrográfica do rio Ivaí

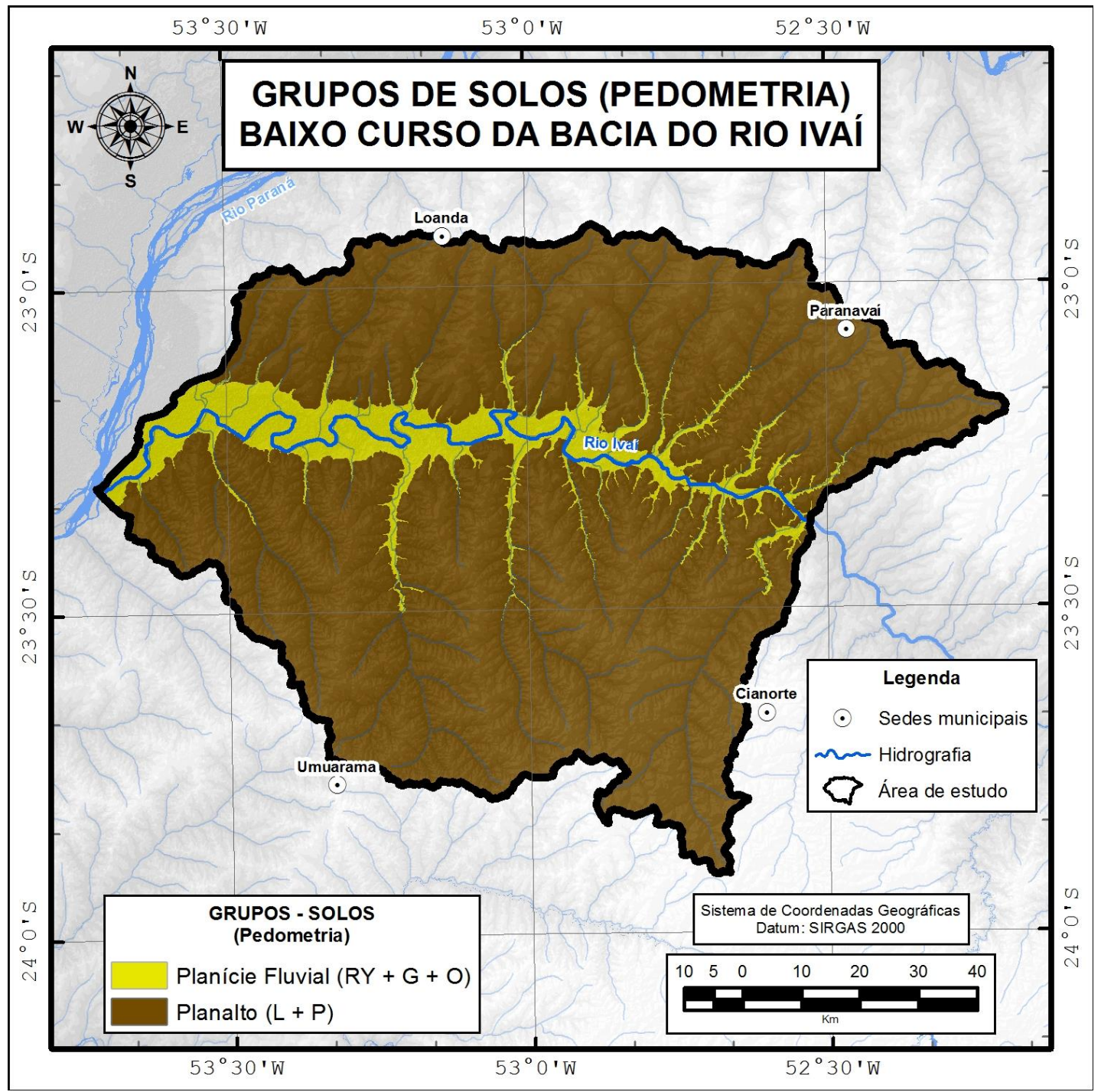

\section{CONSIDERAÇÕES FINAIS}

O uso da pedometria com o método de tabulação cruzada entre o índice de posição topográfica e o índice topográfico de umidade modificado se mostrou satisfatório no mapeamento de porções da paisagem com solos característicos da planície fluvial. A partir dos resultados desta pesquisa, foi possível chegar a um mapeamento mais detalhado (1:50.000) que os mapas de meio físico existentes, principalmente o mapa de solos do estado do Paraná (1:250.000).

Solos localizados nessas planícies, como Neossolos Flúvicos, Gleissolos e Organossolos, são difíceis de serem mapeados em campo principalmente pela dificuldade de acesso e com isso a pedometria se mostra como uma ferramenta muito útil, uma vez que pelo mapeamento preditivo foi possível espacializar os solos da área de planície fluvial, utilizando 
a integração de diferentes atributos topográficos, sobretudo os dois índices empregados nesse trabalho.

Essa fase pode ser definida como preliminar, ou seja, ela permite a delimitação da área de planície, mas não possibilita a distinção das classes de solos, para isso etapas pontuais de campo associadas a fotointerpretação da área são necessárias.

\section{REFERÊNCIAS}

BÖHNER, J.; SELIGE, T. Spatial prediction of soil atributes using terrain analysis and climate regionalisation. In: Böhner, J., McCloy, K.R., Strobl, J. [Eds.]: Göttinger Geogr. SAGA - Analyses and Modelling Applications. Abh, n. 115, 2006.

BURROUGHS, P. A.; BOUMAB, J.; YATESC, S. R. The state of the art in pedometrics. Geoderma, Amsterdam, v. 62, n. 3, p. 311-326, 1994.

CHRISTOFOLETTI, A. Geomorfologia. 2. Ed. São Paulo, Editora Edgard Blucher, 2011.

DALMOLIN, R. S. D.; TEN CATEN, A. Mapeamento Digital: nova abordagem em levantamento de solos. Investigación Agraria, v. 17, p. 77-86, 2015.

EMBRAPA (Empresa Brasileira de Pesquisa Agropecuária). Mapa de Solos do Estado do Paraná. Escala 1:250.000. Rio de Janeiro: Embrapa Solos, 2007.

EMBRAPA (Empresa Brasileira de Pesquisa Agropecuária). Sistema Brasileiro de Classificação de Solos. Centro Nacional de Pesquisa de Solos. 3. Ed. Rio de Janeiro: Embrapa Solos, 2013.

FERNANDES, L.A.; COIMBRA, A.M. O Grupo Caiuá (Ks): Revisão estratigráfi ca e contexto deposicional. Revista Brasileira de Geociencias, v.24(3):164-176, 1994.

HENGL, T. Pedometric mapping: bridging the gaps between conventional and pedometric approaches, Tese (Doutorado). Wageningen University, Enschede, 236 f. 2003.

HUNG, M. N. W. B.; SIEFERT, C. A. C.; SANTOS, I. Simulação hidrogeomorfológica da dinâmica das áreas saturadas da bacia do rio corredeiras, Rio Negrinho -SC. RA'E GA: o Espaço Geográfico em Análise. Curitiba, v.41 Temático de Geomorfologia, p. 208-227, 2017.

HUTCHINSON, M. F. Calculation of hydrologically sound digital elevation models. Paper presented at Third International Symposium on Spatial Data Handling at Sydney, Australia, 1989.

IBGE (Instituto Brasileiro de Geografia e Estatística). Manual técnico de geomorfologia. 2. Ed. Rio de Janeiro: IBGE, 2009. 
IBGE (Instituto Brasileiro de Geografia e Estatística). Coordenação de Recursos Naturais e Estudos Ambientais. Manual técnico de pedologia. 3. Ed. Rio de Janeiro, 430 p. 2015

McBRATNEY, A. B.; ODEH, I. O. A.; BISHOP, T. F. A.; DUNBAR, M. S.; SHATAR, T. M. An overview of pedometric techniques for use in soil survey. Geoderma, v. 97, n. 3-4, p.293-327, 2000.

McBRATNEY, A. B.; MENDONÇA-SANTOS, M. L.; MINASNY, B. On digital soil mapping. Geoderma, v. 117, p. 3-52, 2003.

LEPSCH, I. F. 19 lições de Pedologia. São Paulo: Oficina de Textos, 2011.

MOORE, I. D.; GESSLER, P. E.; NIELSEN, G. A.; PETERSON, G. A. Soil attribute prediction using terrain analysis. Soil Science Society American Journal. v. 57, p. 443-452, 1993.

NAKASHIMA, P. Sistemas pedológicos da região noroeste do Estado do Paraná: distribuição e subsídios para o controle da erosão. São Paulo, Tese (Doutorado em Geografia Física) Faculdade de Filosofia, Letras e Ciências Humanas, Universidade de São Paulo, 1999.

NOWATZKI, A.; SANTOS, L. J. C.; PAULA, E. V. Utilização do Sig na delimitação das áreas de preservação permanente (APP's) na Bacia do Rio Sagrado (Morretes/PR). Revista Sociedade \& natureza (UFU. Online), v. 22, p. 121-134, 2010.

NOWATZKI, A.; JARENTCHUK JUNIOR, O.; PAULA, E. V. O contexto geográfico e ambiental das Áreas de Preservação Permanente. Terr@ Plural (UEPG. Online), v. 10, p. 23 34, 2016.

NOWATZKI, A.; SANTOS, L. J. C.; SILVEIRA, C.T. Potencialidade do Índice de Posição Topográfica no Mapeamento Pedológico Preditivo em uma Sub-Bacia do Rio CapricórnioPR. Revista do Departamento de Geografia (USP), v. 34, p. 10-20, 2017.

PARANÁ. Resolução Conjunta IBAMA/SEMA/IAP N 005, de 28 de março de 2008. Casa Civil Governadoria do Poder Executivo do Estado do Paraná. Curitiba, PR, 2008.

SAMUEL-ROSA, A. O que é Pedometria? Newsletter da Comissão de Pedometria da Sociedade Brasileira de Ciência do Solo. n. 1, 2013. Disponível em: <https://sites.google.com/site/pedometria/home>. Acesso em: 22 jun. 2017.

SANTOS, L.J.C.; FIORI, C.O.; CANALI, N.E.; FIORI, A.P.; SILVEIRA, C.T.; SILVA, J.M.F; ROSS, J.S. 2006. Mapeamento Geomorfológico do Estado do Paraná. Revista Brasileira de Geomorfologia. Ano 7, n 2, 2006.

SILVA, J. M. F.; OKA-FIORI, C.; SILVEIRA, C. T. Índice de Diversidade de Formas de Relevo do Setor Norte da Apa da Serra da Esperança (PR) com Emprego de Técnica de Classificação Geomorfométrica. Revista do Departamento de Geografia USP, Volume Especial - Eixo 6, p.112-123, 2017. 
SILVEIRA, C. T. OKA-FIORI, C.; SANTOS, L. J. C.; SIRTOLI, A. V.; SILVA, C. R.; BOTELHO, M. F. Soil prediction using artificial neural networks and topographic attributes. Geoderma Vol. 172. 165-172, 2013.

SILVEIRA, R. M. P.; SILVEIRA, C. T. Análise digital do relevo aplicada à cartografia geomorfológica da porção central da serra do mar paranaense. Revista Brasileira de Geomorfologia, v. 17, nº 4, 2016.

TOMLIN, C. D. Map algebra: One perspective. Landscape and Urban Planning, 30(1-2), 3-12. 1994.

WEISS, A. Topographic position and landforms analysis. Poster presentation, ESRI User Conference, San Diego, CA, 2001. 